Roberts, while worried about many of the same issues, fears that the reforms may "depoliticise" and therefore weaken the NHS: "The fact that the government takes a position at all is exactly what makes medicine in the United Kingdom so different from that in America. The United States government avoids dealing with medical care as much as possible, recognising that whatever policies are instituted some major constituency will be offended... in the last presidential election neither George Bush nor Michael Dukakis offered a specific statement on health care... The great gap is not between Americanisation and socialised medicine. It is between a system run by business versus one run by politics, by the standards of the market versus those of public discourse." As someone who has spent about a quarter of a century in each country, I would find it hard to disagree.

GORDON BEST

King's Fund College, London W2 4HS

1 Light D. Learning from their mistakes? Health Service fournal 1990;100:1470-2.

2 Light D. Bending the rules. Health Service fournal 1990;100:1513-5.

3 Light D. Labelling waste as inefficiency. Health Service fournal 1990;100:1552-3.

+ Light D. Biting hard on the research hit. Health Service fournal 1990;100:1604-5.

Light D. Medical house arrest. Health Service fournal 1990;100:1648-9.

6 Roberts J. Navigating the seas of change. BMF 1991;302:34-7.

7 Roberts J General practice: feeling fine, getting better. $B M 7$ 1991:302:97-100.

8 Roberts J. A medical maise in hospit. $B M \mathcal{F} 1991 ; 302: 163-6$;

9 Roberts J. Junior doctors' years: training not education. BM7 1991;302:225-8.

\title{
Physical signs of sexual abuse in children
}

\section{Skill and experience needed to find and interpret}

Many sexually abused children show no physical signs, and even when signs believed to be indicative of sexual abuse are present the diagnosis should very rarely be made on these alone. Confirmation depends on multidisciplinary investigation. The most important single feature, if it is available, is a statement by the child; this may be supported by medical and forensic evidence, an admission by the abuser, and comprehensive assessment of the child, family, and social background. All are fallible guides to diagnosis, which should be approached with caution and humility, knowing the serious consequences of diagnostic error in either direction.

Though physical signs are only one part of the evidence in cases of possible child sexual abuse, they have been a controversial part, particularly the significance of anal findings. Following the Cleveland controversy and the ButlerSloss report, ${ }^{1}$ the Royal College of Physicians of London set up a working party to consider these physical signs - their terminology, how they should be elicited, and what was known of their significance. Its report, published this week, shows the relatively subsidiary role of physical signs in this diagnosis. ${ }^{2}$ The report sets out in detail how the anogenital region should be examined and by whom and discusses the significance of the appearances that may be seen and the varying degrees of confidence with which they may be regarded as signs of abuse.

Some children have evidence of both sexual and other physical abuse; violent sexual abuse may be associated with bruising around the knees, thighs, and genitalia. The report concentrates, however, on signs present in the genital area in girls and the anal region in both sexes. A detailed examination of these regions has not been part of the training of most paediatricians, and skill and experience are needed both to avoid further trauma to the child and to make accurate observations and interpret them correctly. The working party therefore recommends that a few doctors in each district should be trained and should see enough children to acquire these skills.

Anal and genital appearances change with the position of the child and the technique of examination, and the report's second practical recommendation is that these should be standardised. The place and circumstances of the examination, the approach to the child, and the methods used should be designed to reassure the child and to prevent unnecessary distress, and of course no force or restraint should be used. The anogenital examination should be done as part of a full general examination, and usually towards the end of the examination.
The structure and appearances in girls of the external genitalia, particularly the hymen, vary, and the report has useful diagrams and descriptions. The only signs considered diagnostic of abuse are laceration or scars of the hymen and attenuation of the hymen with loss of tissue. Other signs, such as an enlarged hymenal opening (more than $1 \mathrm{~cm}$ in horizontal diameter in a prepubertal girl), notches or bumps in the hymen, or localised erythema or oedema, may support the diagnosis of sexual abuse. All these signs need to be interpreted with caution in the light of normal variation.

Interpreting anal signs that may indicate anal penetration has been even more difficult and controversial. The report has a glossary of 18 terms used to describe presumed anal signs of child sexual abuse. It tries to establish a more uniform nomenclature and to indicate the possible significance of each sign, which is uncertain for most of them. The report concludes that the only absolute indicator of anal abuse is a laceration or healed scar extending beyond the anal mucosa on to the perianal skin in the absence of a reasonable alternative explanation such as major trauma. Signs supportive but not diagnostic of anal abuse are anal laxity without other explanation, "reflex anal dilatation" of more than $1 \mathrm{~cm}$, erythema, swelling, fissures, venous congestion, and bruising.

Reflex anal dilatation has been the most controversial single sign in discussions of child sexual abuse. This is relaxation of both the external and internal anal sphincters on separating the buttocks, so that the anus presents a cylindrical hole with a clear view into the rectum. The technique of examination is especially important - the longer the buttocks are separated to view the anus, the more likely it is to gape open, and the working party recommends an observation period no longer than 30 seconds. The argument has been whether reflex anal dilatation is usually a sign of repeated anal penetration or whether it occurs normally (studies quote incidences of $4 \%$ to $15 \%$ ) or as a result of conditions such as chronic constipation and Crohn's disease. The evidence reviewed by the working party is highly conflicting, and the working party understandably seems to have had difficulty reaching a definite conclusion. It believes that reflex anal dilatation of more than 2 $\mathrm{cm}$ is more likely than not to be associated with abuse, while dilatation of more than $1 \mathrm{~cm}$ is a possible supporting sign.

The physical signs attributed to sexual abuse are not unique in requiring experience to elicit and interpret them and in having limited sensitivity and specificity for the conditions they are meant to help diagnose. Making a diagnosis on the basis of a single physical sign is very rarely possible in 
medicine. With child sexual abuse it is particularly dangerous to try to do so because of the devastating social consequences of an incorrect diagnosis. The emphasis of the working party's report on the subsidiary role of physical signs in this diagnosis - as well as on the absence of physical signs in many sexually abused children (even if physical signs have been present they may disappear with the passage of time)-is prudent.

The details in the report about examination methods, and on other matters such as the collection of forensic samples and when to look for sexually transmitted disease, will be valuable to the corps of doctors whom it recommends should specialise in this work. These doctors' workload has greatly increased and will continue to do so, which should be taken into account in assessing paediatric staffing requirements of districts.

Associate editor, $B M \mathcal{F}$

ROGER ROBINSON

1 Butler-Sloss E. Report of the inquiry into child abuse in Cleveland 1987. London: HMSO, 1988 2 Royal College of Physicians Working Party. Physical signs of sexual abuse in children. London: RCP. 1991.

\section{Postoperative urinary retention in men}

\section{Don't automatically blame the prostate}

Postoperative retention of urine may happen after any surgical operation, even without pre-existing urinary symptoms. When it occurs in men aged over 50 underlying bladder outlet obstruction from prostatic hypertrophy is often assumed to be causing it, acute retention simply being precipitated by the added effects of surgery and postoperative pain. This assumption is based on the knowledge that prostatic hypertrophy is common, with nearly one in three 40 year olds needing a prostatectomy by the age of $80,{ }^{1} 40 \%$ of them presenting with acute retention. ${ }^{2}$ Thus if a man aged over 50 with postoperative retention fails to void normally a few days after his catheter is removed, custom dictates that he should proceed to a prostatectomy, albeit at a time when he is physically and mentally least prepared for it.

Better understanding of the physiology and pathophysiology of micturition suggests that such management is wrong in most cases. The smooth muscle of the bladder is innervated by cholinergic neurones, while the bladder neck and proximal urethra are rich in $\alpha$ adrenergic receptors; surgery in general, and anaesthetic agents in particular, can profoundly affect the function of these organs. For example, atropine and other anticholinergic anaesthetic reversal agents (some with a half life of three to four days) will depress detrusor contractility, leading to reduced bladder power. ${ }^{3}$ At the same time, stress induced sympathetic activity will increase bladder neck and proximal urethral tone, thus increasing outlet resistance. ${ }^{+}$ Opiates given at operation and postoperatively will suppress the bladder signal to micturate..$^{5}$ Taken together, these may cause a bladder that has been filled (or even overfilled) by intravenous infusion to decompensate (remember Starling's Law on cardiac smooth muscle) - reducing the ability of the detrusor muscle to initiate contraction. ${ }^{6}$ Finally, the postoperative patient will find toileting difficult, being immobilised by connection to intravenous infusions, central venous pressure lines, cardiac monitors, and the like, and may, between analgesic administration, experience pain sufficient to inhibit the perineal relaxation necessary for the initiation of micturition.

Given these facts, incriminating the prostate gland as the sole cause of postoperative retention is questionable. In this issue, Anderson and Grant ( $p$ 894) ${ }^{7}$ describe managing a group of patients with postoperative retention by clean intermittent self catheterisation. Of their 32 patients, urodynamic assessment was performed in 22, of whom only five had objective evidence of bladder outlet obstruction. The rest had low pressure voiding, amounting to detrusor failure in eight. All these resumed normal micturition after a variable period of intermittent catheterisation (mean two months; range 6-32 weeks). Automatically performing prostatectomy in men aged over 50 with postoperative retention is therefore right in only a few cases. In spite of its continuing appearance in surgical textbooks, ${ }^{89}$ the belief that postoperative retention occurs mainly in men with "prostatism" now seems like another "urological myth."

Postoperative urinary retention may affect any patient, at any age, and of either sex and will have an iatrogenic cause (anaesthetics, bladder overdistension, pharmacologically reduced perception) in about four out of five cases. Short term pharmacological manipulation with indoramin (an $\alpha$ blocker) and bethanechol (a cholinergic agent) may be worth trying. If this fails emptying the bladder by intermittent catheterisation or by an indwelling suprapubic catheter is the management of choice. Not all elderly men will master the art of self catheterisation, and in those who cannot an indwelling suprapubic catheter is preferable to a urethral catheter. This avoids the complications of infection and stricture and permits occasional clamping to assess micturition capability without repeated removal and replacement.

In postoperative retention, as in so many other conditions referred to surgeons, knowledge of the underlying pathophysiology is essential to identify those who will benefit from surgery and those who will not.

Consultant Urological Surgeon,

P H O'REILLY

Stepping Hill Hospital,

Stockport SK2 7JE

1 Glynn RJ, Campion EW, Bouchard GR, Silbert JE. The development of benign prostatic hyperplasia among volunteers in the normative aging study. Am $\mathcal{F}$ Epidemiol 1985;121:78-90. 2 Craigen AA, Hickling JB, Saunders CRG, et al. Natural history of prostatic obstruction, prospective survey. $\mathcal{F} R$ Coll Gen Pract 1969;18:226-32.

Virtanen R, Kanto J, Lisalo E, et al. Pharmacokinetic studies on atropine with special reference to age. Acta Anaesthesiol Scand 1982;26:297-300.

4 Gosling JA, Dixon JS, Lendon RG. The autonomic innervation of the human male and female bladder neck and proximal urethra. $\mathcal{F}$ Urol 1977;118:302-5.

5 Dray A. Epidural opiates and urinary retention: new models provide new insights. Anesthesiology 1988;68:323-4.

6 Petros JG, Bradley TM. Factors influencing post-operative urinary retention in patients undergoing surgery for benign anorectal disease. Am f Surg 1990;159:374-6.

7 Anderson JB, Grant JBF. Postoperative retention of urine: a prospective urodynamic study. BMF 1991;302:894-6.

8 Mitchell JP. Retention of urine. In: Dudley HAF, ed. Hamilton Bailey's emergency surgery. 11 th ed Bristol: Wright, 1986:507.

9 Ellis $\mathrm{H}$, Calne RY. The prostate. In: Lecture notes on general surgery. 7th ed. Oxford: Blackwell Scientific, 1987:362.

10 Foster MC, Upsdell SM, O'Reilly PH. Urological myths. BMF 1990;301:1421-3.

\section{Correction}

Picking up the tab for erythropoietin

This editorial by Dr Roger Gabriel (2 February, p 249) incorrectly stated the Department of Health's position on prescription of growth hormone by family doctor. Mr Kenneth Clarke, when Secretary of State for Health, stated that family doctors can prescribe these drugs if they see fit, and not that they should be prescribed by family doctors, as published. 